\title{
Author Correction: Lipid peroxidation regulates long-range wound detection through 5-lipoxygenase in zebrafish
}

Anushka Katikaneni, Mark Jelcic, Gary F. Gerlach, Yanan Ma, Michael Overholtzer (i) and Philipp Niethammer (D)

Correction to: Nature Cell Biology https://doi.org/10.1038/s41556-020-0564-2, published online 31 August 2020.

In the version of this Letter originally published, the morpholino sequences in the Methods section 'morpholino injections' were incorrect. “One-cell-stageembryoswere injected with 2.3 nl of 250-500 $\mu$ Mduox morpholino 1(MO1:5'-AAGCGTCACTTACTATAATGTTGGA-3'; Gene Tools) or misprime morpholino (MP: 5'-TCCCTTTTAGAATTTACCTTGCCGA-3'; Gene Tools) ${ }^{2}$, together with $200 \mu \mathrm{M}$ p53 morpholino (5'-ATGCTCAACTATAATGTTGGACATT-3'; Gene Tools) ${ }^{38}$ diluted in water" should instead read "One-cell-stage embryos were injected with $2.3 \mathrm{nl}$ of 250-500 $\mu \mathrm{M}$ duox morpholino 1 (MO1: 5'- AGTGAATTAGAGAAATGCACCTTTT-3'; Gene Tools) or misprime morpholino (MP: 5' - AGTcAATTAcAGAAATcCAgCTaTT - $3^{\prime}$; Gene Tools) ${ }^{2}$, together with $200 \mu \mathrm{M}$ p53 morpholino (5'- GCGCCATTGCTTTGCAAGAATTG -3'; Gene Tools) ${ }^{38}$ diluted in water." The error has been corrected.

Published online: 13 April 2021

https://doi.org/10.1038/s41556-021-00683-0

(c) The Author(s), under exclusive licence to Springer Nature Limited 2021

\section{Author Correction: Non-canonical Wnt/PCP signalling regulates intestinal stem cell lineage priming towards enteroendocrine and Paneth cell fates}

Anika Böttcher (D), Maren Büttner D , Sophie Tritschler (D), Michael Sterr, Alexandra Aliluev, Lena Oppenländer, Ingo Burtscher, Steffen Sass, Martin Irmler (D), Johannes Beckers, Christoph Ziegenhain (D), Wolfgang Enard, Andrea C. Schamberger, Fien M. Verhamme, Oliver Eickelberg (D), Fabian J. Theis (D) and Heiko Lickert (D)

Correction to: Nature Cell Biology https://doi.org/10.1038/s41556-020-00617-2, published online 4 January 2021

In the version of this Letter originally published, one of the analysed single-cell RNA sequencing samples contained cell duplicates from another sample (Control_7_FVR (with 90\% FVR enrichment) contained the cells from sample Control_5_FVR (with 50\% FVR enrichment)) due to an error that occurred during processing of single-cell RNA-seq libraries in the cell ranger pipeline. None of the conclusions change, but this affects the plots and maps shown in Figs 3b-e and 5a-d, Extended Data Figs. 4c-g, 5 and $8 \mathrm{~b}-\mathrm{f}$, and source data for Fig. $3 c$. The original and corrected images are shown below, and the errors in the paper have been corrected. 